\title{
To Assess the Association between Exchange Rate, Commodity Prices and Cryptocurrency in Indonesia
}

\author{
Nur Hussain: Morgan State University, United States of America.
}

\begin{abstract}
The paper aimed to assess the association among exchange rate, commodity prices and crypto currency in Indonesia. This study is quantitative in which the data has been gathered from the Investing.com from 2016 to 2020. The variables which were considered in the study include exchange rate, gold prices, cotton prices, oil prices, Bitcoin and Ethereum. In terms of the analysis, the vector autoregression and granger causality test has been adopted.The results of this study identified that there is no effect of exchange rate, oil price, cotton price and gold price on Bitcoin. On the other hand, there is only significant effect of gold prices on Ethereum. The results of this study are restricted to Indonesian context and the data has been considered from 2016 to 2019 due to the lack of data on crypto currency.
\end{abstract}

Key words: Exchange rate, Oil price, Gold price, Cotton price, Bitcoin, Ethereum, Indonesia.

\section{Introduction}

In light of the study conducted by Erdas and Caglar (2018) it was found that money cannot be considered as means of exchange but now it also refers to store of value, standard of deferred payment and an commodity. Money is influenced by various factors such as technological advances and internet data. With the advancement of technology and rapid globalisation, electronic currencies are commonly used and many market transactions are carried out through virtual currencies. One of the popular virtual currency that has gripped the market is Bitcoin that helps in instant electronic payments. It consist of block chain technology and unlike the conventional note systems, Bitcoin does not have any physical form nor does the Government Issue it.

Despite of the prevailing criticism over its legal, technical and safety issues, Bitcoin has gained increased interest and attention from the internet users (Murphy, Murphy, \& Seitzinger, 2015). The previous studies that are conducted in similar domain have not yet analysed relationship or the causality testing with commodity prices and exchange rate. Therefore, this study explores and investigates the association between exchange rate, commodity prices and cryptocurrency in case of Indonesia.

Many researchers investigated whether Bitcoin is a currency or asset but it was found that it is considered as a financial asset only and is not suitable or effective for purchasing goods and services (Glaser, Zimmermann, Haferkorn, Weber, \& Siering, 2014). In addition to this, the researchers also reached to this conclusion that the volatility of Bitcoin is higher than other currencies. Yermack (2013) found that virtually there is no association in daily exchange rate of Bitcoin with dollar's exchange rate. Another study conducted by Chen, Pandey, and Dba (2014) revealed that Bitcoin cannot be used as medium of exchange but it is more suitable as an investment asset and can play a vital role in improving investor's portfolio. 


\section{Literature Review}

There is a growing interest of academicians and researchers on Bitcoin given its rapid rise in popularity amongst economists and analysts. In light of the basic functions of money that are: store of value, unit of exchange, and unit of account, the research carried out by Yermack (2013) have evaluated that whether Bitcoin can be regarded as money or not. The analysis of Yermack's findings show that as compared to the widely used currencies, the volatility of Bitcoin is much higher, this characteristic tends to undermine the usefulness of Bitcoin as unit of account and medium of exchange. The findings have further postulated that dollar exchange rate and the daily exchange rate of Bitcoin have no correlation.

There are other researches that have shed light upon the relationship between Bitcoin, stock prices, and commodity prices, Glaser et al. (2014) analysed the perception of user for Bitcoin as a currency or as an asset. The results of this research concluded that Bitcoin is a currency which is not used for buying commodities or assets, it is rather used for financial speculation. Similarly, another study was carried out by Chen et al. (2014) for determining the purpose of Bitcoin. The results of the research indicated that it might not be a suitable currency used for exchange however, it can play a considerable role in improving the efficiency of investor's portfolio. Baek and Elbeck (2015) made comparison of stock market index and Bitcoin volatility through their research. The results of this research precisely showed that Bitcoin is 23 times more volatile as compared to S\&P 500.

As per the research of Narayan, Falianty, and Tobing (2019) Indonesia Digital Asset Exchange ("Indodax") is one of the largest Indonesian cryptocurrency exchange. On average, the daily transaction of D10million US dollar is being performed with this exchange within Indonesia. Furthermore, Kusumastuty, Wulandari, Narmaditya, and Kamaludin (2019) in his research has defined that there is zero correlation determined between cryptocurrency and daily exchange rate within Indonesia as compared to the exchange rate of other economies, which mainly includes British pound, US dollar, Gold, Yen and much more. On the other hand, Pati (2019) in his research has evaluated the influence of exchange rate and cryptocurrency on the Indonesian Stock market. It has been analysed that a noticeable impact of the exchange rate and cryptocurrency has been observed, and it produces a vital impact on the value of cryptocurrency.

Furthermore, Bufala (2019) in his research has examined the influence of bitcoin on the gold prices. It has been evaluated that bitcoins are sufficient for gold prices, and it provides vital results within the investment processes. The high fluctuations in the exchange rate of bitcoins, which is considered safe in which the investment can be done, and the desired results can be obtained. A noticeable influence of the bitcoin prices has been observed in association with gold and it has been categorised as a speculative asset having a positive impact on the economic factors and long-term results can be obtained.

H3: There is a relationship between gold prices and bitcoin.

Furthermore, Andrean (2019) in his research has examined the influence of exchange rate and cryptocurrency on the oil prices. It has been evaluated that a significant impact of oil prices is present on the value of cryptocurrency in terms to have long-term results. In contrast to this, Makarov and Schoar (2020), in his research has evaluated that either cryptocurrency should be considered as currency or asset. After evaluating various aspects, it has been deduced that cryptocurrency is considered as a speculative financial asset. This can be used as an investment asset. On the contrary, it has been evaluated that cryptocurrency is not suitable to be considered as an exchange currency, however, it can be used to enhance the efficiency of the investor portfolio. This can be used to invest in different categories in which oil is the most highlighted. However, it has been described-above that an essential impact of the exchange rate and cryptocurrency is observed on the oil prices, which can also be used to perform various investments within the respective field. H4: There is a relationship between oil prices and bitcoin.

There was another study conducted by Atik, Kose, Y1lmaz, and Saglam (2015) where the relationship between exchange rate and Bitcoin as determined in the context of Turkey. A number of trading currencies were analysed in this study. The final results of this research indicated that thee was existence of one-way relationship between Japanese yen and Bitcoin. Dwyer (2015) conducted a research aimed towards comparing variance of Bitcoin returns with foreign exchange and gold. The results depicted that the variance of returns in the case of Bitcoin are relatively higher than gold and foreign exchange. Bouoiyour and Refk (2015) conducted a research where the relationship between returns of Bitcoin and gold and silver was assessed. 
Optimal-GARCH method was used for the purpose of testing their relationship. The results of this research indicate that in the short-run Bitcoin is a rather weak hedge relative to the long-run.

Time-series analysis was conducted in order to find out the relationship between different economic indicators and the Bitcoin (Georgoula, Pournarakis, Bilanakos, Sotiropoulos, \& Giaglis, 2015). From the results of this research it was analysed that Bitcoin value has an inverse relationship with exchange rate of EUR and USD. Furthermore, the findings of this research suggested that there is a negative relationship of Bitcoin and S\&P 500. Icellioglu and Ozturk (2017) carried out a research where both short run and long run relationship of Bitcoin with different exchange was studied. Granger causality test and Johansen cointegration tests were applied in this research, however, both long and short run relationship were found to be statistically insignificant.

Dirican and Canoz (2017) carried out a research on Bitcoin have influence over the investor's decision with the help of Autoregressive Distributed Lag Model. There were different indices considered in this research, among which US stock market indices and Chinese stock market indices appeared to have relationship with Bitcoin prices. From this perspective it can be stated that the investors that invest in these indexes can be influenced by the price of Bitcoin. However, there were other indices for which no significant influence was found such as FTSE100 and BIST100. Poyser (2017) has conducted a research to determine the nexus between price of Bitcoin and different micro and macroeconomic variables via a Bayesian Approach. The result for the pair of Yuan and USD showed negative association of Bitcoin price with gold price and investor and attention. On the other hand, the result for the pair of Euro and USD showed positive association of Bitcoin price with gold price and investor and attention.

Based on the hypothesis formed in the above section, following is the conceptual model which was followed to analyse the relationship between exchange rate, commodity prices, and Bitcoin price in Indonesia:

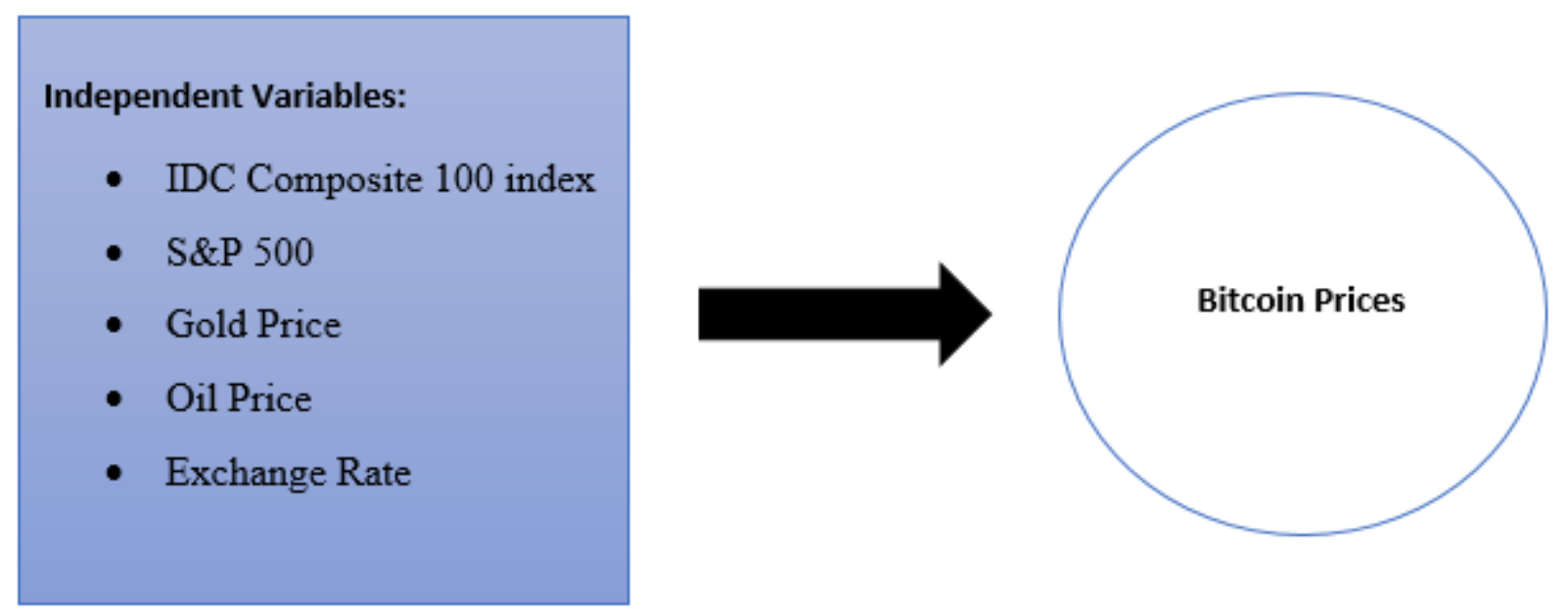

Figure-1. Conceptual model.

As shown in the above conceptual diagram, there are different factors that comprise of independent variable. Fundamentally, exchange rate and commodity prices are the independent variables. As this study is based on Indonesia hence the stock index selected for this research is IDC composite 100 index. Moreover, S\&P 500 has also been selected as the predictor in the conceptual model which shows the market capitalisation-weighted index of 500 largest US companies traded on the stock market based on their market value. The two commodities which tends to impact the stock price and the overall capital market are mainly gold and oil, hence the other two predictors in the conceptual model are gold prices and oil prices. The last factor of the independent variable is the exchange rate where Rupiah is measured against the value of American Dollar. All the aforementioned variables tend to influence Bitcoin prices, the dependent variable as per the research topic is cryptocurrency is the criterion variable. Bitcoin is selected in this regard because it is considered as the pioneer among other kinds of cryptocurrencies.

Narayan et al. (2019) in his research has examined the typical theory of fiat money. It has been evaluated that it is analysed that the principle that bitcoin, which is the commodity money without gold. This theory 
further defines that fiat money without any state and the credit money without any debt defines that bitcoin is not any gold, debt banking or state. Pati (2019) in his research has further stated the relationship between the bitcoin pricing and selected exchange rate based on the GARCH models. However, it has been determined that the GARCH model highlights the influence of conditional variance present in between the US dollar and bitcoins and other stable currencies. This theory further defines the volatility, efficiency and liquidity of the bitcoin markets traded by different firms. This defines that is not considered as a reliable instrument despite the high yield. Furthermore, it has been identified that the bitcoin market is considered vulnerable because of the numerous risks and speculations identified within the respective market. On the other hand, Erdas and Caglar (2018), in his research has studied the short and long-run relationship between the selected exchange and bitcoin. This theory is significant because it provides essential information regarding the casualty relation regarding selected exchange and bitcoin. After analysing this theory, it has been identified that there is no such association present between other exchanges and bitcoin.

It has been further evaluated from the research of Erdas and Caglar (2018) which define that there is no such relation determined among the traditional assets and bitcoin that is being traded specifically in countries like Indonesia. There is a small ratio but essential correlations are determined between bitcoin and various Indonesian assets, which mainly includes oil and gold. Moreover, it has been identified that bitcoin can be used as a diversification tool because of the low correlation value in comparison with the traditional instruments. This allows vital measures to be used within the investment portfolio. Bitcoins are used mostly as a speculative investment and it does not use as an alternative currency or any medium of exchange. Moreover, noticeable domination of the bitcoin prices has been observed over the exchange currencies, which defines the bitcoin can be used as a secure medium to perform an investment, which can play a significant role in any uncertain situation. This defines that the bitcoin can be used to have a long-term impact, and various positive measures can be obtained accordingly.

\section{Method}

The researcher has used quantitative method alongside secondary data for statistical testing. The data will be collected from existing databases that can be accessed for obtaining commodity prices, exchange rates and bitcoin prices. The data will be collected from 2016 to 2019 (as per availability) on daily basis of prices.

Firstly, descriptive statistics for the variables were calculated in order to assess the statistical characteristics of the variables in the model. As the data was of time-series nature hence unit-root testing was carried out. Existence of unit root means that parametric tests can be applied and if there is no existence of unit root then parametric tests cannot be applied. The following equation shows the t-statistic of $\gamma_{2}$ coefficient:

$$
\Delta p_{t}=\gamma_{0}+\gamma_{1} t+\gamma_{2} p_{t-1}+\sum_{i=1}^{n} n_{i} \Delta p_{t-1}+\varepsilon_{t}
$$

It is assumed that ' $\mathrm{s}$ ' is the stochastic time-series with k-dimensions, and is further influenced by an exogenous variable which is also time-dependent ' $x_{t}$ ' possessing $d$-dimensions then, the VAR model can be formulated below:

$$
s_{t}=A_{1} s_{t-1}+A_{2} s_{t-2}+\cdots+A_{n} s_{t-n}+\varepsilon_{t}
$$

After the transformation of equation which was formed by cointegration of relationship, the following equation was formed:

$$
\begin{gathered}
\Delta s_{t}=\alpha \beta^{\prime} s_{t-1}+\sum_{j=1}^{n-1} \Gamma_{i} \Delta s_{t-1}+\varepsilon_{t} \\
\Pi=\sum_{j=1}^{n} n_{i}-I
\end{gathered}
$$

Research in Social Sciences ISSN: 2641-5305 Vol. 3, No. 1, pp. 1-13 2020 DOI: $10.53935 / 2641-5305 . v 3 i l .36$ Email: Hussain@gmail.com Funding: This study received no specific financial support. Article History: Received: 12 March 2020 Revised: 8 April 2020 Accepted: 4 May 2020 Published: 29 May 2020 () 2020 by the authors; licensee Academic Publishing Group 


$$
\mathrm{n}_{j}=-\sum_{k=j+1}^{n} A_{k}
$$

Further, as cointegrating vector is present, that is why we are moving towards the following equation where $\cap_{\mathrm{s}_{\mathrm{t}-1}} \sim \mathrm{I}(0)$

$$
\Delta s_{t}=\alpha \beta^{\prime} s_{t-1}+\sum_{k=1}^{n-1} n_{j} \Delta s_{t-1}+\varepsilon_{t}
$$

Error correction in the above equation is represented by $\beta^{\prime} s_{t-1}$, hence it can be stated as $e c_{t-1}$ which shows the relationship between variables in the long-run. The equation can be re-written as:

$$
\Delta s_{t}=\alpha e c_{t-1}+\sum_{k=1}^{n-1} n_{j} \Delta s_{t-1}+\varepsilon_{t}
$$

Another test that has been applied on the dataset that is Vector Auto-Regression (VAR) for the purpose of testing causality between variables. The following equation indicates the equation for the VAR testing carried out:

' $\mathrm{ec}_{\mathrm{t}-1}$ ' in the above equation represents the long-term relationship between the variables that are included in the research model. In alignment to this equation, the following equation specifically shows the variables that are incorporated:

$$
\widetilde{L B} \widetilde{P_{t}}=\alpha_{1}+\beta_{1} I D C_{t}+\beta_{2} L S P_{t}+\beta_{3} L G P_{t}+\beta_{4} O P_{t}+\beta_{5} E R_{t}+\epsilon_{t}
$$

Where,

$\mathrm{BP}=$ Bitcoin prices

IDC $=$ IDX composite 100

$\mathrm{SP}=\mathrm{S} \& \mathrm{P} 500$

$\mathrm{GP}=$ Gold price

$\mathrm{OP}=$ Oil price

$\mathrm{ER}=$ Exchange Rate

\section{Results and Analysis}

\subsection{Descriptive Statistics}

The Table 1 depicts the descriptive Statistics of the variables which have been adopted in this study. In this manner, it is evident from the Table 1 that mean value for exchange rate is determined to be 0.00012 which shows that the average mean value for exchange rate of Indonesia against USD is $0.00012 \mathrm{Rp}$. Additionally, the standard deviation for the exchange rate is computed to be 0.003 which posits that the exchange rate of Indonesian rupiah against USD will deviate from $0.003 \mathrm{Rp}$. In addition to this, the mean value for the oil prices is determined to be -0.0001 which depicts that the average oil prices over the years was USD -0.0001. Meanwhile, the standard deviation for oil prices was computed to be 0.033 which depicts that the oil prices will deviate from USD 0.033. On the other hand, the mean value for the gold prices was determined to be 0.0002 which depicts that the average gold price against the Indonesian Rupiah is USD 0.0002. In this manner, the standard deviation for gold prices was computed to be 0.008 which posits that gold prices will deviate from USD 0.008 . With respect to the cotton prices, it has been determined that the mean value for cotton prices is 0.00 which shows that the average cotton prices against the USD were 0.00 . In this manner, the standard deviation for the cotton price was computed to be 0.014 which posits that the cotton prices will deviate from USD 0.014 . The mean value for the gasoline prices was obtained to be 0.00 which shows that the average gasoline price was USD 0.00 while the standard deviation for the gasoline prices was computed to be 0.024 which shows that the gasoline prices will deviate from USD 0.024. Moreover, the mean value for Bitcoin was determined to be 0.002 which depicts that the average price for Bitcoin was USD 0.002 with respect to Indonesian Rupiah while the standard deviation was computed to be 0.042 which shows that the Bitcoin will deviate from USD 0.042. Furthermore, the mean value for Ethereum was determined to be 
0.002 which depicts that the average price for Ethereum was USD 0.002. Additionally, the standard deviation for Ethereum was computed to be 0.059 which posits that the Ethereum will deviate from USD 0.059.

Table-1. Descriptive statistics.

\begin{tabular}{llllll}
\hline Variable & Obs & Mean & Std. Dev. & Min & Max \\
\hline ER (Rp) & 948 & 0.00012 & 0.003 & -0.027 & 0.044 \\
OP (USD) & 946 & -0.0001 & 0.033 & -0.282 & 0.319 \\
GP (USD) & 948 & 0.0002 & 0.008 & -0.047 & 0.055 \\
CP (USD) & 948 & 0.00 & 0.014 & -0.078 & 0.059 \\
GOP (USD) & 948 & 0.00 & 0.024 & -0.329 & 0.139 \\
BTC (USD) & 948 & 0.002 & 0.042 & -0.186 & 0.227 \\
ETH (USD) & 948 & 0.002 & 0.059 & -0.266 & 0.258 \\
\hline
\end{tabular}

\subsection{Augmented Dickey-Fuller (ADF)}

The unit root testing is significant on the basis of the previous patterns in order to forecast the values. According to Paparoditis and Politis (2018) historical values makes it challenging to assess the future values while using the conventional inferential statistics. Therefore, the Augmented Dickey-Fuller (ADF) has been used for the purpose of detecting the unit root.

Table-2. Augmented dickey-fuller (ADF).

\begin{tabular}{lll}
\hline Augmented Dickey-Fuller test statistic & t-Statistic & Prob.* \\
\hline Exchange Rate & -24.050 & 0.000 \\
Gold Price & -25.175 & 0.000 \\
Cotton Price & -28.922 & 0.000 \\
Gasoline Price & -33.385 & 0.000 \\
Bitcoin & -30.245 & 0.000 \\
Ethereum & -28.151 & 0.000 \\
\hline
\end{tabular}

From the above Table 2, the results for Augmented Dickey-Fuller (ADF) can be determined in which null hypothesis is grounded on the fact that there is presence of unit root in the data. In this manner, it can be identified from the above table that there is no presence of unit root in exchange rate, gold price, cotton price, gasoline price Bitcoin and Ethereum as the p-values of all the variables were below the threshold of 0.05 .

\subsection{Vector Autoregression}

The Table 3 depicts the relationship among all the variables with respect to the equations of each variable. In this manner, it can be determined that there is no relationship among the variables with respect to the equation of Bitcoin as p-value is 0.206 which is above the threshold of 0.05 . In addition to this, there is significant relationship among the variables with respect to the equation of gasoline prices as $p$-value is 0.015 which is below the threshold of 0.05 . Moreover, the relationship is also significant among the variables with respect to the equation of gold prices as p-value is 0.025 which is also below the threshold of 0.05 . On the other hand, there is also a significant relationship among the variables with respect to the equation of oil prices as $p$-value is 0.00 . Furthermore, the relationship of variables with respect to the exchange rate is also significant as p-value is 0.00 .

Table-3. Vector autoregression equations.

\begin{tabular}{cccccc}
\hline Equation & Parms & RMSE & R-sq & chi2 & P>chi2 \\
\hline BTC & 15 & 0.040 & 0.031 & 18.009 & 0.206 \\
ETH & 15 & 0.060 & 0.023 & 13.328 & 0.500 \\
GOP & 15 & 0.020 & 0.047 & 27.816 & 0.015 \\
CP & 15 & 0.014 & 0.025 & 14.816 & 0.390 \\
GP & 15 & 0.008 & 0.044 & 26.087 & 0.025 \\
OP & 15 & 0.029 & 0.078 & 47.873 & 0 \\
ER & 15 & 0.004 & 0.068 & 41.146 & 0.000 \\
\hline
\end{tabular}


Moreover, the below Table 4 depicts the vector autoregression with respect to Bitcoin. In this manner, it can be determined that there is significant effect of Ethereum on the Bitcoin as the Ethereum is dependent on the first lag as $B=-0.071[\mathrm{p}=0.043<0.05]$.

Table-4. Vector Autoregression (Bitcoi).

\begin{tabular}{lllll}
\hline & Coef. & Std. Err. & $\mathbf{z}$ & $\mathbf{P}>|\mathbf{z}|$ \\
\hline BTC & & & & \\
BTC & & & & \\
L1. & -0.015 & 0.054 & -0.28 & 0.782 \\
L2. & 0.041 & 0.049 & 0.84 & 0.4 \\
ETH & & & & \\
L1. & $-0.071^{* *}$ & 0.035 & -2.02 & 0.043 \\
L2. & 0.012 & 0.035 & 0.35 & 0.726 \\
GOP & & & & \\
L1. & 0.080 & 0.074 & 1.08 & 0.279 \\
L2. & -0.034 & 0.065 & -0.53 & 0.599 \\
CP & & & & \\
L1. & -0.001 & 0.118 & -0.01 & 0.991 \\
L2. & -0.083 & 0.119 & -0.7 & 0.483 \\
GP & & & & \\
L1. & -0.365 & 0.196 & -1.87 & 0.062 \\
L2. & -0.092 & 0.209 & -0.44 & 0.661 \\
OP & & & & \\
L1. & 0.056 & 0.064 & 0.87 & 0.382 \\
L2. & 0.041 & 0.059 & 0.7 & 0.482 \\
ER & & & & \\
L1. & 0.419 & 0.500 & 0.84 & 0.403 \\
L2. & 0.283 & 0.585 & 0.48 & 0.628 \\
cons & 0.005 & 0.002 & 2.61 & 0.009 \\
\hline
\end{tabular}

Table-5. Vector Autoregression (Ethereum).

\begin{tabular}{|c|c|c|c|c|}
\hline & Coef. & Std. Err. & $\mathbf{z}$ & $\mathbf{P}>|\mathbf{z}|$ \\
\hline \multicolumn{5}{|l|}{ ETH } \\
\hline \multicolumn{5}{|l|}{ BTC } \\
\hline L1. & -0.056 & 0.080 & -0.71 & 0.479 \\
\hline L2. & -0.067 & 0.073 & -0.92 & 0.36 \\
\hline \multicolumn{5}{|l|}{ ETH } \\
\hline L1. & -0.044 & 0.052 & -0.85 & 0.397 \\
\hline L2. & 0.049 & 0.052 & 0.93 & 0.352 \\
\hline \multicolumn{5}{|l|}{ GOP } \\
\hline L1. & 0.079 & 0.109 & 0.72 & 0.47 \\
\hline L2. & -0.059 & 0.097 & -0.61 & 0.539 \\
\hline \multicolumn{5}{|l|}{$\mathrm{CP}$} \\
\hline L1. & 0.081 & 0.175 & 0.46 & 0.644 \\
\hline L2. & 0.024 & 0.177 & 0.13 & 0.893 \\
\hline \multicolumn{5}{|l|}{ GP } \\
\hline L1. & $-0.607 * *$ & 0.291 & -2.09 & 0.037 \\
\hline L2. & 0.012 & 0.311 & 0.04 & 0.97 \\
\hline \multicolumn{5}{|l|}{ OP } \\
\hline L1. & 0.007 & 0.095 & 0.07 & 0.94 \\
\hline L2. & 0.085 & 0.087 & 0.97 & 0.333 \\
\hline \multicolumn{5}{|l|}{ ER } \\
\hline L1. & 0.624 & 0.743 & 0.84 & 0.401 \\
\hline L2. & -0.904 & 0.869 & -1.04 & 0.298 \\
\hline _cons & 0.007 & 0.003 & 2.64 & 0.008 \\
\hline
\end{tabular}

Research in Social Sciences ISSN: 2641-5305 2020

DOI: 10.53935/2641-5305.v3il.36 Email: Hussain@gmail.com

Funding: This study received no specific financial support.

Article History:
Received: 12 March 2020

Revised: 8 April 2020

Accepted: 4 May 2020

Published: 29 May 2020

(C) 2020 by the authors; licensee Academic Publishing Group 
On the other hand, the Table 5 depicts the vector autoregression with respect to Ethereum. In this manner, it can be determined from the below Table 5 that there is significant effect of gold price on Ethereum which is dependent on its first lag as $B=-0.607[p=0.037<0.05]$.

With respect to the vector autoregression of gasoline prices, it can be determined from Table 6 that there is an effect of gold prices on the gasoline prices as the gold price is dependent on it second lag as $\mathrm{B}=-0.301$ $[p=0.003<0.05]$. Moreover, there is also significant effect of exchange rate on the gasoline prices as exchange rate is dependent on its first lag $B=-0.531[p=0.031<0.05]$

Table-6. Vector Autoregression (Gasoline Prices).

\begin{tabular}{|c|c|c|c|c|}
\hline & Coef. & Std. Err. & $\mathbf{z}$ & $\mathbf{P}>|z|$ \\
\hline \multicolumn{5}{|l|}{ GOP } \\
\hline \multicolumn{5}{|l|}{ BTC } \\
\hline L1. & -0.014 & 0.026 & -0.54 & 0.591 \\
\hline L2. & 0.011 & 0.024 & 0.47 & 0.64 \\
\hline \multicolumn{5}{|l|}{ ETH } \\
\hline L1. & 0.014 & 0.017 & 0.8 & 0.424 \\
\hline L2. & -0.023 & 0.017 & -1.34 & 0.179 \\
\hline \multicolumn{5}{|l|}{ GOP } \\
\hline L1. & -0.066 & 0.036 & -1.84 & 0.066 \\
\hline L2. & $0.071 * *$ & 0.032 & 2.23 & 0.026 \\
\hline \multicolumn{5}{|l|}{$\mathrm{CP}$} \\
\hline L1. & -0.005 & 0.058 & -0.08 & 0.934 \\
\hline L2. & 0.061 & 0.058 & 1.05 & 0.293 \\
\hline \multicolumn{5}{|l|}{ GP } \\
\hline L1. & 0.048 & 0.096 & 0.5 & 0.614 \\
\hline L2. & $-0.301 * *$ & 0.103 & -2.93 & 0.003 \\
\hline \multicolumn{5}{|l|}{ OP } \\
\hline L1. & -0.002 & 0.032 & -0.07 & 0.947 \\
\hline L2. & -0.010 & 0.029 & -0.33 & 0.739 \\
\hline \multicolumn{5}{|l|}{ ER } \\
\hline L1. & $-0.531 * *$ & 0.246 & -2.16 & 0.031 \\
\hline L2. & 0.131 & 0.287 & 0.46 & 0.648 \\
\hline cons & 0.000 & 0.001 & 0.47 & 0.635 \\
\hline
\end{tabular}

Table-7. Vector Autoregression (Cotton Price).

\begin{tabular}{lllll}
\hline & Coef. & Std. Err. & $\mathbf{z}$ & $\mathbf{P}>|\mathbf{z}|$ \\
\hline CP & & & & \\
BTC & & & & \\
L1. & -0.013 & 0.019 & -0.69 & 0.49 \\
L2. & -0.012 & 0.017 & -0.68 & 0.495 \\
ETH & & & & \\
L1. & 0.011 & 0.012 & 0.9 & 0.367 \\
L2. & 0.002 & 0.012 & 0.2 & 0.842 \\
GOP & & & & \\
L1. & -0.003 & 0.025 & -0.13 & 0.898 \\
L2. & 0.018 & 0.023 & 0.82 & 0.415 \\
CP & & & & \\
L1. & -0.059 & 0.041 & -1.43 & 0.152 \\
L2. & 0.030 & 0.041 & 0.72 & 0.469 \\
GP & & & & \\
L1. & 0.090 & 0.068 & 1.33 & 0.184 \\
L2. & 0.106 & 0.073 & 1.45 & 0.146 \\
OP & & & & \\
L1. & 0.002 & 0.022 & 0.1 & 0.924 \\
L2. & 0.003 & 0.020 & 0.16 & 0.872 \\
ER & & & & \\
L1. & -0.212 & 0.173 & -1.22 & 0.222 \\
L2. & $0.446^{* *}$ & 0.203 & 2.2 & 0.028 \\
cons & 0.001 & 0.001 & 1.23 & 0.22 \\
\hline
\end{tabular}

Research in Social Sciences ISSN: 2641-5305 Vol. 3, No. 1, pp. 1-13

I. $10.53935 / 2641-5305.13 i 1.36$ Email: Hussain@gmail.com

Funding: This study received no specific financial support.

Article History:
Received: 12 March 2020

Revised: 8 April 2020

Accepted: 4 May 2020

Published: 29 May 2020

(1) 2020 by the authors; licensee Academic Publishing Group 
The Table 7 depicts the Vector Autoregression with respect to the cotton prices. In this manner, it can be determined from the below table that there is significant effect of exchange rate on the cotton prices as the exchange rate is dependent on its second lag as $\mathrm{B}=0.446[\mathrm{p}=0.028<0.05]$.

The Table 8 depicts the vector autoregression with respect to the gold price. On the basis of the below table 8 , it is evident that there is an effect of gasoline prices on gold prices as the gasoline price is dependent on its second lag as $\mathrm{B}=-0.031[\mathrm{p}=0.023<0.05]$. Moreover, the effect of exchange rate is also significant on the gold prices as the exchange rate is dependent on its first lag as $B=-0.282[p=0.008<0.05]$.

Table-8. Vector Autoregression (Gold Price).

\begin{tabular}{lllll}
\hline & Coef. & Std. Err. & $\mathbf{z}$ & $\mathbf{P}>|\mathbf{z}|$ \\
\hline GP & & & & \\
BTC & & & & \\
L1. & 0.005 & 0.011 & 0.4 & 0.686 \\
L2. & -0.009 & 0.010 & -0.86 & 0.389 \\
ETH & & & & \\
L1. & 0.007 & 0.008 & 0.94 & 0.348 \\
L2. & 0.004 & 0.007 & 0.59 & 0.552 \\
GOP & & & & \\
L1. & 0.013 & 0.016 & 0.85 & 0.394 \\
L2. & $-0.031 * *$ & 0.014 & -2.27 & 0.023 \\
CP & & & & \\
L1. & -0.007 & 0.025 & -0.27 & 0.789 \\
L2. & -0.013 & 0.025 & -0.52 & 0.606 \\
GP & & & & \\
L1. & $0.106 * *$ & 0.042 & 2.53 & 0.011 \\
L2. & 0.060 & 0.045 & 1.34 & 0.179 \\
OP & & & & \\
L1. & -0.013 & 0.014 & -0.93 & 0.35 \\
L2. & 0.003 & 0.013 & 0.22 & 0.824 \\
ER & & & & \\
L1. & $-0.282^{* *}$ & 0.107 & -2.64 & 0.008 \\
L2. & -0.012 & 0.125 & -0.09 & 0.926 \\
cons & 0.000 & 0.000 & 0.69 & 0.488 \\
\hline
\end{tabular}

Table-9. Vector Autoregression (Oil Prices).

\begin{tabular}{lllll}
\hline & Coef. & Std. Err. & $\mathbf{z}$ & $\mathbf{P}>|\mathbf{z}|$ \\
\hline OP & & & & \\
BTC & & & & \\
L1. & -0.033 & 0.039 & -0.85 & 0.394 \\
L2. & -0.049 & 0.035 & -1.38 & 0.168 \\
ETH & & & & \\
L1. & 0.019 & 0.025 & 0.75 & 0.454 \\
L2. & -0.015 & 0.025 & -0.59 & 0.555 \\
GOP & & & & \\
L1. & -0.045 & 0.053 & -0.84 & 0.398 \\
L2. & -0.013 & 0.047 & -0.27 & 0.784 \\
CP & & & & \\
L1. & 0.162 & 0.085 & 1.9 & 0.057 \\
L2. & -0.151 & 0.085 & -1.77 & 0.077 \\
GP & & & & \\
L1. & -0.123 & 0.141 & -0.87 & 0.383 \\
L2. & 0.002 & 0.151 & 0.01 & 0.99 \\
OP & & & & \\
L1. & $0.249 * *$ & 0.046 & 5.39 & 0.00 \\
L2. & -0.080 & 0.042 & -1.9 & 0.058 \\
ER & & & & \\
L1. & -0.127 & 0.360 & -0.35 & 0.723 \\
L2. & -0.516 & 0.421 & -1.23 & 0.22 \\
cons & -0.001 & 0.001 & -0.93 & 0.354 \\
\hline
\end{tabular}

Research in Social Sciences ISSN: 2641-5305 Vol. 3, No. 1, pp. 1-13

I: $10.53935 / 2641-5305 . v 3 i 1.36$ Email: Hussain@gmail.com

Funding: This study received no specific financial support.

Article History:

Revised: 8 April 2020

Accepted: 4 May 2020

Published: 29 May 2020

(1) 2020 by the authors; licensee Academic ublishing Group 
The Table 9 depicts the vector autoregression with respect to the oil prices. In this manner, it has been determined that there is no significant effect of variables on the oil prices.

The Table 10 shows the vector autoregression with respect to the exchange rate. In this manner, it can be determined on the basis of the below Table 10 that there is significant effect of oil prices on the exchange rate as oil price is dependent on its second lag as $\mathrm{B}=0.015[\mathrm{p}=0.009<0.05]$.

Table-10. Vector Autoregression (Exchange Rate).

\begin{tabular}{lllll}
\hline & Coef. & Std. Err. & $\mathbf{z}$ & $\mathbf{P}>|\mathbf{z}|$ \\
\hline ER & & & & \\
BTC & & & & \\
L1. & -0.005 & 0.005 & -1.02 & 0.309 \\
L2. & -0.001 & 0.005 & -0.19 & 0.848 \\
ETH & & & & \\
L1. & -0.001 & 0.003 & -0.15 & 0.88 \\
L2. & 0.002 & 0.003 & 0.58 & 0.559 \\
GOP & & & & \\
L1. & 0.001 & 0.007 & 0.08 & 0.933 \\
L2. & 0.010 & 0.006 & 1.54 & 0.125 \\
CP & & & & \\
L1. & 0.015 & 0.012 & 1.28 & 0.201 \\
L2. & 0.003 & 0.012 & 0.28 & 0.782 \\
GP & & & & \\
L1. & 0.017 & 0.019 & 0.88 & 0.377 \\
L2. & -0.004 & 0.020 & -0.18 & 0.856 \\
OP & & & & \\
L1. & -0.008 & 0.006 & -1.28 & 0.201 \\
L2. & $0.015^{* *}$ & 0.006 & 2.59 & 0.009 \\
ER & & & & \\
L1. & $0.168^{* *}$ & 0.049 & 3.44 & 0.001 \\
L2. & $0.190^{* *}$ & 0.057 & 3.33 & 0.001 \\
cons & 0.000 & 0.000 & -0.49 & 0.626 \\
\hline
\end{tabular}

\subsection{Granger Causality Test}

The below Table 11 depicts the results obtained from Granger Causality test. In this manner, it can be determined that the equation of gasoline prices determined to have significant short term effect excluding the gold prices as $\mathrm{B}=8.816[\mathrm{p}=0.012<0.05]$. This depicts that gold price do not granger gasoline prices. In addition to this, the equation of gold prices was also determined to have significant short term effect while excluding the gasoline prices and exchange rate as the p-value for both the variables was below the threshold of 0.05 . This posits that the gasoline prices and exchange rate do not granger gold prices. Moreover, the significant short term effect of oil price equation was also determined while excluding the cotton price as pvalue is determined to be below the threshold of 0.05 . Therefore, the cotton prices do not granger oil price. Furthermore, the equation of exchange rate is also determined to have significant effect while excluding the oil prices as the $\mathrm{p}$-value $<0.05$. In this manner, the oil prices do not granger exchange rate.

The Table 12 depicts the summary of hypothesis and on the basis of this table, it is evident that there is no influence of exchange rate, oil price, cotton price and gold price on Bitcoin. In this manner, the results of this study align with the findings of Glaser et al. (2014) that Bitcoin is a currency which is not used for buying commodities or assets, it is rather used for financial speculation. On the other hand, it has also been determined that there is no influence of exchange rate, oil price and cotton price on the Ethereum. However, the significant influence of gold price on Ethereum was determined. Ti contradicts with the study of Poyser (2017) that there is negative association of cryptocurrency price with gold price and investor and attention. 
Table-11. Granger Causality.

\begin{tabular}{|c|c|c|c|c|}
\hline Equation & Excluded & chi2 & df & Prob $>$ Chi2 \\
\hline \multicolumn{5}{|l|}{ BTC } \\
\hline BTC & ETH & 4.172 & 2 & 0.124 \\
\hline BTC & GOP & 1.728 & 2 & 0.421 \\
\hline BTC & $\mathrm{CP}$ & 0.492 & 2 & 0.782 \\
\hline BTC & GP & 3.673 & 2 & 0.159 \\
\hline BTC & OP & 1.436 & 2 & 0.488 \\
\hline BTC & ER & 1.028 & 2 & 0.598 \\
\hline BTC & ALL & 12.91 & 12 & 0.375 \\
\hline \multicolumn{5}{|l|}{ ETH } \\
\hline ETH & BTC & 1.296 & 2 & 0.523 \\
\hline ETH & GOP & 1.107 & 2 & 0.575 \\
\hline ETH & $\mathrm{CP}$ & 0.225 & 2 & 0.893 \\
\hline ETH & GP & 4.355 & 2 & 0.113 \\
\hline ETH & $\mathrm{OP}$ & 0.974 & 2 & 0.614 \\
\hline ETH & ER & 1.625 & 2 & 0.444 \\
\hline ETH & ALL & 10.164 & 12 & 0.602 \\
\hline \multicolumn{5}{|l|}{ GOP } \\
\hline GOP & BTC & 0.524 & 2 & 0.769 \\
\hline GOP & ETH & 2.372 & 2 & 0.305 \\
\hline GOP & $\mathrm{CP}$ & 1.126 & 2 & 0.569 \\
\hline GOP & GP & $8.816^{* *}$ & 2 & 0.012 \\
\hline GOP & OP & 0.122 & 2 & 0.941 \\
\hline GOP & ER & 4.735 & 2 & 0.094 \\
\hline GOP & ALL & 17.766 & 12 & 0.123 \\
\hline \multicolumn{5}{|l|}{$\mathrm{CP}$} \\
\hline $\mathrm{CP}$ & BTC & 0.913 & 2 & 0.633 \\
\hline $\mathrm{CP}$ & ETH & 0.866 & 2 & 0.648 \\
\hline $\mathrm{CP}$ & GOP & 0.748 & 2 & 0.688 \\
\hline $\mathrm{CP}$ & GP & 3.882 & 2 & 0.144 \\
\hline $\mathrm{CP}$ & OP & 0.039 & 2 & 0.98 \\
\hline $\mathrm{CP}$ & ER & 5.842 & 2 & 0.054 \\
\hline $\mathrm{CP}$ & ALL & 12.141 & 12 & 0.434 \\
\hline \multicolumn{5}{|l|}{ GP } \\
\hline GP & BTC & 0.929 & 2 & 0.628 \\
\hline GP & ETH & 1.274 & 2 & 0.529 \\
\hline GP & GOP & $6.845^{* *}$ & 2 & 0.033 \\
\hline GP & $\mathrm{CP}$ & 0.324 & 2 & 0.85 \\
\hline GP & OP & 0.883 & 2 & 0.643 \\
\hline GP & ER & $7.119 * *$ & 2 & 0.028 \\
\hline GP & ALL & 19.286 & 12 & 0.082 \\
\hline \multicolumn{5}{|l|}{ OP } \\
\hline OP & BTC & 2.550 & 2 & 0.279 \\
\hline OP & ETH & 0.878 & 2 & 0.645 \\
\hline
\end{tabular}

Research in Social Sciences ISSN: 2641-5305 2020

DOI: 10.53935/2641-5305.v3i1.36

Email:Hussain@gmail.com

Funding: This study received no specific

financial support.

Article History:

Revised: 8 April 2020

Accepted: 4 May 2020

Published: 29 May 2020

(C) 2020 by the authors; licensee Academic

Publishing Group 


\begin{tabular}{lllll}
\hline OP & GOP & 0.726 & 2 & 0.695 \\
OP & CP & $7.126^{* *}$ & 2 & 0.028 \\
OP & GP & 0.760 & 2 & 0.684 \\
OP & ER & 1.737 & 2 & 0.42 \\
OP & ALL & 15.982 & 12 & 0.192 \\
ER & & & & \\
ER & BTC & 1.058 & 2 & 0.589 \\
ER & ETH & 0.357 & 2 & 0.836 \\
ER & GOP & 2.404 & 2 & 0.301 \\
ER & CP & 1.680 & 2 & 0.432 \\
ER & GP & 0.813 & 2 & 0.666 \\
ER & OP & $7.655 * *$ & 2 & 0.022 \\
ER & ALL & 14.883 & 12 & 0.248 \\
\hline
\end{tabular}

\section{Discussion and Summary of Hypothesis}

Table-12. Summary of Hypothesis

\begin{tabular}{lll}
\hline Hypotheses & Proposition & Results \\
\hline $\mathrm{H}_{1}$ & There is a significant influence of exchange rate on Bitcoin. & Rejected \\
$\mathrm{H}_{2}$ & There is a significant influence of oil price on Bitcoin. & Rejected \\
$\mathrm{H}_{3}$ & There is a significant influence of cotton price on Bitcoin. & Rejected \\
$\mathrm{H}_{4}$ & There is a significant influence of gold price on Bitcoin. & Rejected \\
$\mathrm{H}_{5}$ & There is a significant influence of exchange rate on Ethereum. & Rejected \\
$\mathrm{H}_{6}$ & There is a significant influence of oil price on Ethereum. & Rejected \\
$\mathrm{H}_{7}$ & There is a significant influence of cotton price on Ethereum. & Rejected \\
$\mathrm{H}_{8}$ & There is a significant influence of gold price on Ethereum. & Accepted \\
\hline
\end{tabular}

\section{Conclusion and Recommendations}

With the advancement of technology, it has been realised by researchers and policy makers that money cannot be considered as means of exchange but now it also refers to store of value, standard of deferred payment and an commodity. In this manner, this study has been conducted for the purpose of assessing the association among exchange rate and commodity prices and crypto currency in Indonesia. In this manner, the data has been gathered from Investing.com while the variables considered for commodity include gold, cotton and oil. The data has been analysed using the vector autoregression and granger causality. The results of this study identified that there is no effect of exchange rate, oil price, cotton price and gold price on Bitcoin. On the other hand, there is only significant effect of gold prices on Ethereum. In this manner, it is suggested for the policy makers to increase the emphasis over gold prices for the purpose of ensuring sustainability in the prices of crypto currency.

\section{Limitations and Future Implications}

The results of this study are restricted to Indonesian context therefore, it is suggested for the future researchers to focus on other countries as well with respect to determining the effect of exchange rate on crypto currency. On the other hand, the data has been considered from 2016 to 2019 due to the lack of data on crypto currency. In this manner, it is suggested to future researchers to increase the sample size for the purpose of presenting significant findings. 


\section{References}

Andrean, G. (2019). Determinant of the bitcoin prices as alternative invesment in Indonesia. IndicatorsJournal of Economic and Business, 1(1), 22-29.

Atik, M., Kose, Y., Y1lmaz, B., \& Saglam, F. (2015). Crypto currency: Bitcoin and effects on exchange rates. The Journal of Faculty of Economics and Administrative Sciences, 6(11), 247-261.

Baek, C., \& Elbeck, M. (2015). Bitcoins as an investment or speculative vehicle? A first look. Applied Economics Letters, 22(1), 30-34. Available at: https://doi.org/10.1080/13504851.2014.916379.

Bouoiyour, J., \& Refk, S. (2015). What does Bitcoin look like? Annals of Economics \& Finance, 16(2), 449492.

Bufala, J. (2019). The validity of cryptocurrency (bitcoin) as object of commodity and comparasion with Singapore legal system.

Chen, W. Y., Pandey, V. K., \& Dba, C. (2014). The value of Bitcoin in enhancing the efficiency of an investor's portfolio. Journal of Financial Planning, 27(9), 44-52.

Dirican, C., \& Canoz, I. (2017). The cointegration relationship between Bitcoin prices and major world stock indices: An analysis with ARDL model approach. Journal of Economics Finance and Accounting, 4(4), 377-392. Available at: https://doi.org/10.17261/pressacademia.2017.748.

Dwyer, G. P. (2015). The economics of Bitcoin and similar private digital currencies. Journal of Financial Stability, 17, 81-91.

Erdas, M. L., \& Caglar, A. E. (2018). Analysis of the relationships between Bitcoin and exchange rate, commodities and global indexes by asymmetric causality test. Eastern Journal of European Studies, 9(2), 27-45.

Georgoula, I., Pournarakis, D., Bilanakos, C., Sotiropoulos, N. D., \& Giaglis, M. G. (2015). Using time-series and sentiment analysis to detect the determinants of Bitcoin prices, MCIS 2015 Proceedings 20, Samos, 3-5 October.

Glaser, F., Zimmermann, K., Haferkorn, M., Weber, M. C., \& Siering, M. (2014). Bitcoinasset or currency? Revealing users' hidden intentions, in: Avital, M., Leimeister, M. and Schultze, U. (eds). Paper presented at the Proceedings of the European Conference on Information Systems, Israel: Tel Aviv.

Icellioglu, C., \& Ozturk, M. (2017). In search of the relationship between Bitcoin and selected exchange rates: Johansen test and granger causality test for the period 2013-2017. Maliyeve Finans Yazllarl, 109, 5170.

Kusumastuty, C. A., Wulandari, D., Narmaditya, B. S., \& Kamaludin, M. (2019). Do monetary variables affect to cryptocurrency price? Lesson from Indonesia. Journal of Economics and Development Studies, 11(2), 131-142.

Makarov, I., \& Schoar, A. (2020). Trading and arbitrage in cryptocurrency markets. Journal of Financial Economics, 135(2), 293-319. Available at: https://doi.org/10.1016/j.jfineco.2019.07.001.

Murphy, E. V., Murphy, M. M., \& Seitzinger, M. V. (2015). Bitcoin: Questions, answers, and analysis of legal issues. Paper presented at the Library of Congress, Congressional Research Service.

Narayan, S. W., Falianty, T., \& Tobing, L. (2019). The influence of oil prices on Indonesia's exchange rate. Bulletin of Monetary Economics and Banking, 21(3), 303-322. Available at: https://doi.org/10.21098/bemp.v21i3.1007.

Paparoditis, E., \& Politis, D. N. (2018). The asymptotic size and power of the augmented Dickey-Fuller test for a unit root. Econometric Reviews, 37(9), 955-973. Available at: https://doi.org/10.1080/00927872.2016.1178887.

Pati, U. K. (2019). The regulation of cryptocurrency investation in Indonesia. Paper presented at the In 3rd International Conference on Globalization of Law and Local Wisdom (ICGLOW 2019). Atlantis Press.

Poyser, O. (2017). Exploring the determinants of Bitcoin's price: An application of Bayesian structural time series. arXiv preprint arXiv: 1706.01437.

Yermack, D. (2013). Is Bitcoin a real currency? An economic appraisal (No. w19747). National Bureau of Economic Research, 36(2), 843-850. 